\title{
Peronea arteria magna
}

\author{
Lisa H. Betz • Bradford W. Betz
}

Received: 21 January 2009 /Revised: 23 February 2009/Accepted: 11 March 2009/Published online: 21 April 2009

(C) Springer-Verlag 2009

A 10-year-old girl was evaluated with MR angiography for left lower extremity varicosities. The arterial phase MIP (Fig. 1) demonstrated an incidental peronea arteria magna $(P A M)$ of the right calf and a conventional left trifurcation ( $A T$ anterior tibial artery, $P$ peroneal artery, $P T$ posterior tibial artery).

Anomalous branching of the trifurcation results in a dominant peroneal artery in $7-12 \%$ of the population, and PAM, in which the peroneal artery is the only vascular supply to the foot, occurs in $0.2-5.3 \%$ [1, 2]. Patients with congenital or acquired peroneal arterial dominance, especially PAM, are at risk of foot ischemia if this vessel is traumatized, affected by stenoocclusive disease, or harvested as part of a free fibular graft. Preharvest imaging, such as with MR angiography, has been advocated because patients with peroneal arterial dominance can have normal distal pulses [1].

\section{H. Betz}

Department of Biology, Park Science Building,

Bryn Mawr College,

101 North Merion Ave.,

Bryn Mawr, PA 19010, USA

B. W. Betz $(\bowtie)$

Department of Diagnostic Radiology,

Spectrum Health and Helen DeVos Children's Hospital,

100 N. Michigan Ave. NE,

Grand Rapids, MI 49503, USA

e-mail: brad.betz@spectrum-health.org

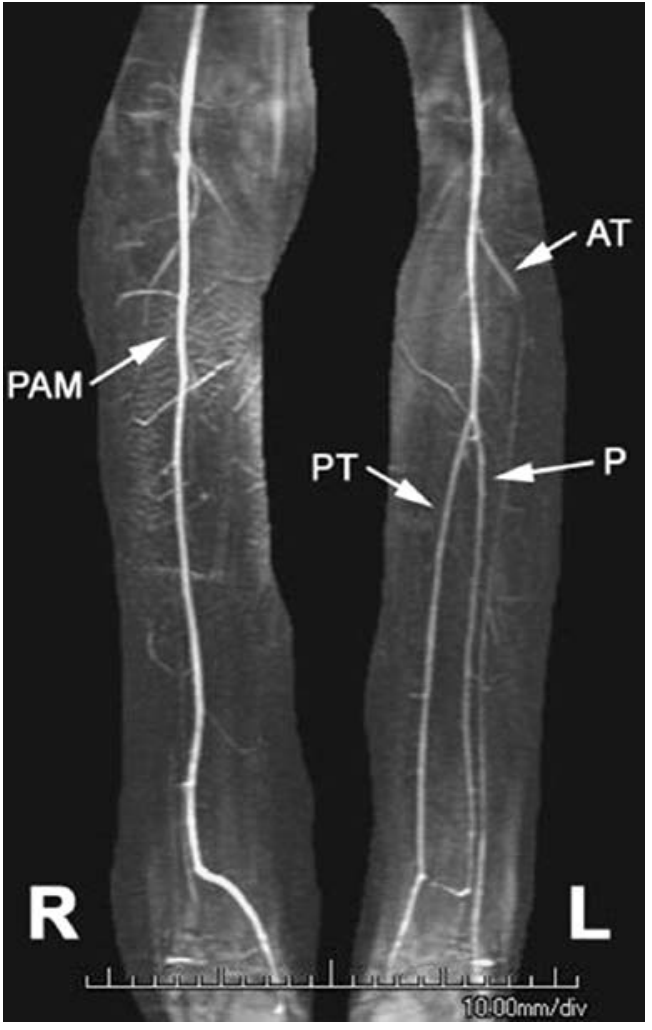

Fig. 1 Arterial phase MIP of the lower extremities

\section{References}

1. Lohan DG, Tomasian A, Krishnam M et al (2008) MR angiography of lower extremities at $3 \mathrm{~T}$ : presurgical planning of fibular free flap transfer for facial reconstruction. AJR 190:770-776

2. Rosson GD, Singh NK (2005) Devascularizing complications of free fibula harvest: peronea arteria magna. J Reconstr Microsurg 21:533-538 